\title{
Correction to: Emergency department screening and interventions for substance use disorders
}

Kathryn Hawk ${ }^{*}$ and Gail D'Onofrio

\section{Correction to: Addict Sci Clin Pract (2018) 13:18 https://doi.org/10.1186/s13722-018-0117-1}

In the version of this article that was originally published [1], some information in the "Background" section was erroneously omitted. This has now been corrected in this Correction note.

\section{Background}

Individuals with SUDs regularly access emergency care, with nearly half of all 4.9 million drug-related ED visits in 2010 categorized as relating to substance use disorders [5].

The original article can be found online at https://doi.org/10.1186/s1372 2-018-0117-1.
Received: 23 April 2019 Accepted: 30 May 2019

Published online: 16 July 2019

\section{Reference}

1. Hawk and D'Onofrio Addict Sci Clin Pract (2018) 13:18 https://doi. org/10.1186/s13722-018-0117-1.

\section{Publisher's Note}

Springer Nature remains neutral with regard to jurisdictional claims in published maps and institutional affiliations. 